УАK 343.13

ББК 67.410 .2

DOI 10.22394/1682-2358-2020-6-62-70

L.M. Fetishcheva, Candidate of Sciences (Law), Docent of the Criminal Process and Criminalistics Department, Perm Institute of the Federal Penitentiary Service of Russia, Lieutenant Colonel of Internal Service

\section{LEGAL REGULATION \\ OF THE PENAL \\ ENFORCEMENT \\ INSPECTORATE \\ EMPLOYEES' POWERS \\ IN THE \\ IMPLEMENTATION \\ OF PREVENTIVE \\ MEASURES \\ IN THE FORM \\ OF HOUSE ARREST}

Topical issues of Penal Enforcement Inspectorate employees' powers at the implementation of criminal executive suppression measures in the form of house arrest are considered. Examples of problematic issues that arise when the implementation of house arrest by PEI officers is not regulated by law, are given. Conclusions are drawn about the need to amend both the criminal procedure legislation and other normative legal acts in order to optimize the work of PEI officers.

Key words and word-combinations: house arrest, preventive measure, Penal Enforcement Inspectorate.
М.М. ФетищеВа, кандидат юридиеских наук, дочент кафедри уголовного процесса и криминалистики Пермского института ФСИН России, подполковник внутренней службъ (email: lidiafetisheva@mail.ru)

\section{ПРАВОВОЕ РЕГУАИРОВАНИЕ ПОАНОМОЧИЙ СОТРУАНИКОВ УГОАОВНО- ИСПОАНИТЕ $Ь$ ВЫХ ИНСПЕКЦИЙ ПРИ РЕААИЗАЦИИ МЕРЫ ПРЕСЕЧЕНИЯ В ВИАЕ АОМАШНЕГО АРЕСТА}

\footnotetext{
Аннотация. Рассматриваются актуальные проблемы правового регулирования полномочий сотрудников уголовно-исполнительных инспекций при реализации меры уголовно-процессуального пресечения в виде домашнего ареста. Приводятся примеры проблемных моментов, возникающих при законодательной нерегламентированности реализации домашнего ареста сотрудниками УИИ. Делаются выводы о необходимости внесения изменений как в уголовно-процессуальное законодательство, так и в другие нормативно-правовые акты с целью оптимизации работы сотрудников УИИ.

Ключевые слова и словосочетания: домашний арест, мера пресечения, уголовно-исполнительная инспекция.

B настоящее время происходит активное реформирование уголовного и угомовно-процессуацьного законодательства. Так, значительные изменения претерпеки
} 
меры уголовно-процессуального пресечения, в частности домашний арест. После преобразования данной меры ее исполнение возложено на учреждения ФСИН России, а именно на уголовно-исполнительные инспекции (УИИ), однако реализаџия этой меры пресечения сотрудниками УИИ в УПК РФ не указана. Аействия УИИ при исполнении домашнего ареста регулируются подзаконными ведомственными нормативными правовыми актами [1]. Аанное законное урегулирование осушествления этой меры пресечения порождает большое количество вопросов у действующих сотрудников УИИ.

Подобная работа по своей сути не явмяется уголовно-процессуальной, ее необходимо рассматривать как сопутствующую. Таким образом, выполняя служебные обязанности по контролю за реализацией меры пресечения в виде Аомашнего ареста, сотрудники УИИ не являются участниками уголовного судопроизводства, так как согласно уголовно-процессуальному статусу они не принимают участия в установлении оснований с целью избрания Аанной меры пресечения и не имеют права обращаться в суд Аля ее изменения ици отмены.

В рамках реализации обозначенного контромя УИИ обязана взаимодействовать с субъектами органов предварительного расследования. Успешное осуществление механизма контроця возможно исключительно на основе взаимного сотрудничества между указанными органами.

С целью обеспечения контроля за нахождением подозреваемого (обвиняемого), в отношении которого мерой пресечения избран домашний арест, работники УИИ в определенном порядке принимают решение о применении аудиовизуальных, эмектронных и иных технических среАств контромя (их совокупность составцяет систему электронного мониторинга подконтрольных Аиџ (СЭМПА) [2] . Порядок применения таких среАств ФСИН России утвержден постановлением Правительства Российской Федерации от 18 февраля 2013 г. № 134 [3] ; он вкмючает в себя инструкцию по организации исполнения наказаний и мер уголовно-правового характера без изоляции от общества, утвержденную приказом Минюста России от 20 мая 2009 г. № 142 (Аалее - Инструкция) [4] .

Согласно п. 22 Инструкщии, в проџессе первоначального разговора с подозреваемым (обвиняемым) работник УИИ доводит до него ряд сведений:

- права и обязанности;

- специализированные мероприятия профилактики, в том числе возможность Аанного миџа обратиться в органы соџиальной защиты насемения Аля оказания помощи при тяжелом материальном положении (например, Аля оформления документа, удостоверяющего мичность);

- последствия при оказании противоправных мер, которые повлекут за собой нарушение нормального расследования уголовного дела;

- требования выполнения меры пресечения в виде домашнего ареста, ответственность за их нарушение [5]; 
- возможность замены домашнего ареста в случае нарушения избранной меры на более строгую меру - заключение под стражу.

Рассмотрим некоторые проблемы правового регулирования, связанного с осуществлением полномочий сотрудниками УИИ при реализаџии меры пресечения в виде домашнего ареста. В орган дознания, орган предварительного слеАствия, а также в суА подозреваемый или обвиняемый доставцяется транспортом УИИ. Именно эту проблему указывают сотрудники УИИ как одну из основных. В частности, следователь должен за трое суток отправить в УИИ поручение о Аоставке Аиџа, в отношении которого назначен домашний арест. Как отмечают сотрудники УИИ, такой срок нереАко нарушается в ходе преАварительного слеАствия, и УИИ увеАомляется менее чем за трое суток.

Особое внимание следует обратить на хронометраж трудового Аня работника УИИ, согласно которому Аля соответствующего исполнения рабочих вопросов при имеющейся штатной численности мюбому работнику необходимо в среднем не меньше шести часов в день на реализацию контроля за одним Аиџом, находящимся поА Аомашним арестом. Следует учитывать, что в это время входит и доставка подозреваемого (обвиняемого) в орган расследования, а также в суд, которые, как правицо, располагаются за пределами граниџ района, где проживает данное киџо. Это приводит к продолжительному отсутствию работника УИИ на служкбе и мешает дальнейшему качественному осуществлению контроця, в отношении подозреваемого (обвиняемого), состоящего на учете в УИИ. Так, девятнадцать из сорока районных филиалов Тверской области (47,5\% от общего количества филиалов) имеют в штате по одному работнику УИИ. Учитывая территориальную удаленность филиалов, возникают определенные проблемы в его замещении на период отсутствия (Аоставка подозреваемых, обвиняемых в орган предварительного расследования, а также в суА) [6] .

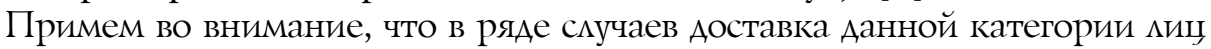
в правоохранительные органы, возможна только автомобильным транспортом, который, как правило, не оснащен средствами защиты и тревожной сигнализацией, что не гарантирует мичной безопасности сотрудников.

Например, Свободненским городским судом было вынесено постановление об избрании меры пресечения в виде домашнего ареста с 14 января 2016 г. Подозреваемый (обвиняемый) числился за СО МО МВА России «Свободненский», впослеАствии за Свободненским городским судом. Местом жительства и содержания под Аомашним арестом явмялось жилое помешение, расположенное в п. Бурея Амурской области. Расстояние от п. Бурея до г. Свободный и обратно составмяет 600 км. В марте и апреле 2016 г. подозреваемый (обвиняемый) доставцялся в г. Свободный по три раза в месяџ [7].

Еще одним примером может послужить постановление судьи Архаринского районного суда от 23 марта 2016 г. об избрании меры пресечения в виде домашнего ареста. Подозреваемый (обвиняемый) числияся за

64 Bulletin of the Volga Region Institute of Administration • 2020. Vol. 20. № 6 
СС УФСКН России по Амурской области, а затем за Архаринским районным судом. Местом жительства и содержания под домашним арестом явцялось жияое помешение, расположенное в с. Белоярово Амурской обмасти. Расстояние для доставки подозреваемого в суд от с. Новокиевский Увац Мазановского района (место дислокаџии филиала по Мазановскому району ФКУ УИИ УФСИН России по Амурской обкасти) до с. Архара и обратно составляет 700 км. В период с марта по август 2016 г. подозреваемый (обвиняемый) доставлялся в Архаринский районный суд восемь раз. Затем мера пресечения была изменена на подписку о невыезде [7].

Нередки также случаи доставки подозреваемых (обвиняемых), проживающих в населенных пунктах, расположенных на значительном удалении от следственного органа, к начацу рабочего дня, поэтому, чтобы доставить подозреваемого к назначенному времени, сотрудники выезжают ночью.

Сложность возникает и при поступлении заявок на доставку подозреваемых и обвиняемых на психиатрическую экспертизу в психоневрологический диспансер. Например, в г. Благовещенске в таких заявках было отказано в соответствии с п. 32 Порядка [8] и ч. 12 ст. 107 УПК РФ, гАе

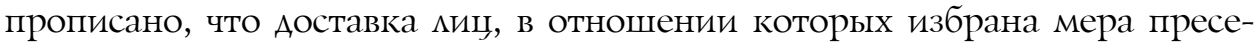
чения в виде домашнего ареста, осушествцяется только в органы дознания, следственные органы и суд. В связи с этим следствием было выдано поручение (заявка) о доставке мица, находящегося по домашним арестом, в следственный комитет г. Благовешенска [7] .

Следующей проблемой явмяется невыполнение норм, прописанных в правовых актах. Так, до настояшего времени ФСИН России не выделена дополнительная штатная численность в количестве 2467 штатных единиц, предусмотренная Федеральным законом от 7 декабря 2011 г. № 420-Ф3 «О внесении изменений в Уголовный кодекс Российской Федерации и отдельные законодательные акты Российской Федерации».

Законодательно не урегулирован и вопрос запрета на общение с опредеценными миџами. В связи с этим у работников УИИ возникают трудности при осушествлении контроля за подозреваемым (обвиняемым). Как правило, такими циџами являются свидетели, проходящие по конкретному уголовному делу. Если следователю законом предоставлено право вызывать

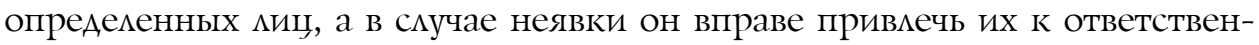
ности, установценной законом, и принудить к исполнению данного законного требования, сотрудник УИИ подобным правом не надемен. Аиџа, с которыми подозреваемому (обвиняемому) судом запрешено общаться, могут отказаться являться в филиал и предоставлять сотрудникам УИИ какую-либо информаџию. Ответственность за неисполнение законного требования сотрудника УИИ законодательно не предусмотрена.

Правовой проблемой явмяется и реализация функщий УИИ по контролю за соблюдением подозреваемым (обвиняемым) запретов и (ияи) ограничений на отправку и получение почтово-телеграфных отправлений, использование 
средств связи и информационно-телекоммуникационной сети «Интернет». В УПК РФ не учтена система реализации УИИ функщий контроля за собмюдением подозреваемым (обвиняемым) таких запретов. Исполнение этих функций предполагает наличие возможности немедменно получать информацию об использовании подозреваемым (обвиняемым) имеющихся в его распоряжении средств связи, а такжке незамедиительно получать информацию о соединениях межАу абонентами и (ияи) абонентскими устройствами, вкАючая Интернет. Обвиняемый может пользоваться Интернетом как с домашнего компьютера, так и в интернет-кафе, осуществить звонок с чужого сотового телефона и сообщить или получить необходимую информацию, которую до судебного заседания он знать не должен. В подобном случае проверить сведения или предоставить доказательства, подтверждающие несоблюдение подозреваемым (обвиняемым) этих запретов и (или) ограничений, УИИ не вправе, ибо законодательно таких полномочий ФСИН России не имеет.

Следующей проблемой исполнения домашнего ареста явмяется отсутствие реальной возможности обратиться в суА с ходатайством о замене подозреваемому (обвиняемому) избранной меры пресечения. Это связано с тем, что первоначально работники УИИ Аолжны обратиться в органы предварительного расследования о замене меры пресечения.

Полагаем, что все перечисленные сложности исполнения домашнего ареста сотрудниками УИИ обусловлены прежде всего недостаточной законодательной регламентаџией его применения. Они требуют комплексной Аоработки, так как объективно не могут быть урегулированы только мишь внесением соответствующих дополнений и изменений в УПК РФ (некоторые ученые полагают, что необходимо разработать и принять федеральный закон о домашнем аресте, устанавливающий правила и порядок исполнения данной меры пресечения). Несомненно, что разрешение вопросов, образующихся при осуществлении контроля за нахождением миц, подозреваемых (обвиняемых) в совершении преступлений, в местах исполнения меры пресечения в виде домашнего ареста, возможно только при выработке эффективных механизмов взаимодействия контролирующего органа (ФСИН России) с органами предварительного расследования, прокуратурой и судом. В связи с этим существует ведомственный контроль и прокурорский наАзор за реализаџией домашнего ареста.

Ведомственный контроль за работниками УИИ проводится федеральным органом исполнительной власти, осуществцяющим правоприменительные функщии, функции по контролю и надзору в сфере исполнения уголовных наказаний в отношении осужденных $(\mathrm{OKИН)}$. Прокурорский надзор представмяет собой деятельность федеральных государственных органов прокуратуры по обеспечению законности, выявлению, устранению и преАупреждению нарушений закона [9] .

При реализации судебных решений по поводу назначенной меры пресечения в виде Аомашнего ареста у сотрудников УИИ могут возникнуть 
различного рода трудности и проблемы. В ходе ведомственного контроля часто выявцяются постановления суда, устанавливающие запрет, не предусмотренный санкщией статьи (запрет без определения конкретных миц). Нередко устанавливаются запреты и ограничения, которые противоречат Аруг Аругу. Осуществление ведомственного контроля происходит на всех стадиях деятельности УИИ, что является его отличительной особенностью от Аругих видов контроля.

На основании приказа Минюста России от 22 августа 2019 г. № 185 [10] ОКИН осуществляет ведомственный контроль за соблюдением законодательства Российской Федерации о службе в УИС в виде ведомственных проверок законности служебной деятельности и принятых решений учреждений и органов УИС, а также их соответствия требованиям законодательства Российской Федераџии о службе в УИС и нормативно-правовым документам Министерства юстиции России и ФСИН России (ведомственные проверки). Основным назначением ведомственного контроля выступает неукоснительное соблюдение прав, свобод и законных интересов подконтрольных миц. Порядок реализации ведомственного контроля устанавливается нормативными правовыми актами и обозначен в УИК РФ [11, ст. 21].

В целях такого контроля за исполнением домашнего ареста ФСИН России преАпринимаются конкретные меры:

- ведомственные проверки соблюдения сотрудниками УИИ законоАательства;

- сбор информации о соблюдении сотрудниками УИИ законодательства;

- мероприятия по устранению выявленных недостатков при соблюдении сотрудниками УИИ законодательства Российской Федерации о службе в УИС.

В пределах ведомственного контроля реализуется функциональный контроль по охране гражданских прав, обращенный, как правило, на охрану прав подконтрольных миџ в наиболее важных сферах [12]. Oсобое внимание удемяется тому, насколько четко сотрудниками УИИ организована деятельность по повышению результативности системы контроля за мицами, находящимися под рассматриваемой мерой пресечения; глубине изучения детерминант совершения миџами, состоящими на учете, новых преступцений; контролю срока, в который принимаются к нарушителям меры воздействия, установленные законом; качеству организаџии сотруАничества с правоохранительными органами в субъектах РФ [13].

В ходе проведения служебной проверки по факту уклонения от контромя обвиняемого, состоящего на учете в филиале по Соликамскому району, и несанкционированного съема им электронного браслета установлен факт несвоевременного выявления нарушений с использованием СЭМП $\Lambda$ и несвоевременное реагирование на допущенное нарушение, а также несвоевременное информирование о поступившем тревожном сообщении фимиала дежурным оператором СЭМПА. Выявленные недостатки привели к 
тому, что обвиняемый скрылся от контроля, утерял электронный браслет, причинив тем самым материальный ущерб. В результате Авое сотрудников были привлечены к дисциплинарной ответственности [14].

В целом можно утверждать, что территориальными органами ФСИН РФ сегодня принимаются надлежашие меры по предупреждению нарушений законности в деятельности УИИ при осуществлении меры пресечения в виде домашнего ареста. Ведомственный контроль необходим дмя справеАливой оџенки истинной ситуации и формирования предпосылок Амя оптимизации деятельности УИИ.

Прокурорский надзор начинается с момента избрания меры пресечения в виде домашнего ареста. Прокурор обязан участвовать при данном процессуальном действии, потому что эта мера пресечения избирается в соответствии со ст. 108 УПК РФ. Согласно приказу Генерального прокурора РФ от 28 декабря 2016 г. № 826, мнение прокурора по ходатайству следователя при избрании домашнего ареста не домжно непременно совпадать с мнением следователя (Аознавателя), а также со стороной обвинения [15]. Прокурор, участвующий при избрании меры пресечения, реализует важнейшую функщию надзора как за органами расследования, так и за защитой законных прав и свобод кичности.

Полномочия прокурора по надзору за исполнением законов сотрудниками УИИ закреплены Федеральным законом «О прокуратуре РФ» [16, ч. 2, ст. 1], но в данных нормах не прописаны полномочия прокурора в сфере контромя за работниками УИИ при реализации домашнего ареста. На наш взгляА, необходимо урегулировать этот вопрос на законоАательном уровне и внести изменения в соответствующие нормативноправовые акты полномочия прокурора.

После принятия к реализаџии УИИ постановления суда об избрании меры пресечения в виде домашнего ареста осуществцяется постановка подконтрольных миџ на учет, который домжен проходить в период всего назначенного судом срока домашнего ареста. С целью проверки полноты и своевременности постановки подконтрольных киџ на учет в УИИ прокурор производит сверку полученных из суда данных с записями в журналах учета, учетными карточками и кичными делами подконтрольных. При исследовании указанных данных по заполняемым реквизитам можно обнаружить нарушения закона.

При необходимости прокурор сопоставцяет с материалами мичных дел подконтрольных Аиџ информаџию, содержащуюся в различного характера карточках, регистрационных цистах, документов по проверкам инспекции по месту нахождения подконтрольного миџа. Аیя проверки правильности ведения УИИ учета подконтрольных киц, совершивших повторные преступцения кибо правонарушения, прокурором запрашиваются соответствующие Аанные из органов, расследующих преступления, которые сопоставляются с Аанными учета, имеющимися в инспекции. 
Отметим, что при реализации домашнего ареста имеются нарушения со стороны УИИ. В 2016 г. в ФКУ УИИ ГУФСИН России по Пермскому краю поступило три акта прокурорского реагирования на нарушения, выявленные при осуществлении контроля за подозреваемыми (обвиняемыми), в отношении которых избрана мера пресечения в виде Аомашнего ареста. Были установлены следующие нарушения:

- ненадлежкащий контроль за подозреваемыми (обвиняемыми), в отношении которых судом избрана мера пресечения в виде домашнего ареста;

- несвоевременная регистрация судебных решений об избрании меры пресечения в виде домашнего ареста в журналах входящих документов и учета $и ц$, в отношении которых избрана мера пресечения в виде домашнего ареста;

- несвоевременное проведение проверки после назначения судебного заседания по факту уклонения от контроля обвиняемого, в отношении которого избрана мера пресечения в виде домашнего ареста, отсутствие мер к розыску обвиняемого, в том числе с привлечением сотрудников МВА.

По итогам проведения служебных проверок нарушения, выявленные

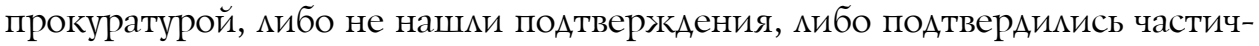
но, Аибо ПодтвеРАИлись Полностью. В результате три сотрУАНИКа привлечены к Аисџиплинарной ответственности [14].

Приведенные сведения свидетельствуют о том, что в действующем угомовно-процессуальном законодательстве не урегулирован вопрос необходимых полномочий у сотруАников УИИ и по исполнению мер пресечения. Необходимо решить вопрос с Аоставкой подконтрольных миц, находящихся под мерой пресечения в виде Аомашнего ареста, в органы следствия и Аознания. Полагаем, что дия доставления подозреваемого (обвиняемого) цемесообразно привлекать автомобильный транспорт не только УИИ, но и органов предварительного расследования, что повысит продуктивность общей работы, а также увеличит взаимодействие между этими органами. Следует регламентировать порядок доставления подозреваемого (обвиняемого) работниками УИИ и органами предварительного расследования в цемях устранения вопросов и проблем взаимодействия между ними.

Аля Аальнейшего развития ведомственного контроля и прокурорского надзора при реализации домашнего ареста требуется законодательно урегулировать полномочия прокурора в данной сфере. Это приведет к прозрачности прокурорских проверок реализации домашнего ареста и поставит четкие рамки Аля ведомственного контроля.

\section{Библиографический список}

1. Пупышева Л.А. Процессуальный статус сотрудников уголовно-исполнительных инспекций // Ведомости УИС. 2018. № 8 (195). С. 35-49.

2. Афанасьев М.В. Осуществление контроля за подозреваемыми и обвиняемыми при избрании к ним меры пресечения в виде домашнего ареста // Ведомости УИС. 2016. № 9 (172). C. $37-42$. 
3. О порядке применения аудиовизуальных, электронных и иных технических средств контроля, которые могут использоваться в целях осуществления контроля за нахождением подозреваемого или обвиняемого в месте исполнения меры пресечения в виде домашнего ареста, а также за соблюдением возложенных судом запретов подозреваемым или обвиняемым, в отношении которого в виде меры пресечения избран запрет определенных действий, домашний арест или залог: постановление Правительства Российской Федерации от 18 февр. 2013 г. № 134 // Российская газета. 2013. № 39.

4. Об утверждении Инструкции по организации исполнения наказаний и мер уголовноправового характера без изоляции от общества: приказ Минюста Российской Федерации от 20 мая 2009 г. № 142. URL: http://www.consultant.ru/document/cons_doc_LAW_89167/

5. Медведев A.A. Уголовно-исполнительные инспекции как субъекты системы профилактики правонарушений // Ведомости УИС. 2019. № 1 (200). С. 38-41.

6. Обзор применения меры пресечения в виде домашнего ареста учреждениями УИИ ФСИН России по Тверской области за 2019 г. URL: https://fsin.gov.ru/news/index. php?ELEMENT_ID=199319

7. Обзор проблемных вопросов, возникающих в деятельности ФКУ УИИ УФСИН России по Амурской области в процессе исполнения судебных решений в отношении лиц с мерой пресечения в виде домашнего ареста за 12 месяцев 2016 г. URL: https://28. fsin.gov.ru/index.php?day $=12 \&$ month $=7 \&$ year $=2016$

8. Об утверждении Порядка осуществления контроля за нахождением подозреваемых или обвиняемых в месте исполнения меры пресечения в виде домашнего ареста и за соблюдением ими наложенных судом запретов и (или) ограничений: приказ Министерства юстиции РФ, МВД России, Следственного комитета РФ, ФСБ России и Федеральной службы РФ по контролю за оборотом наркотиков от 11 февр. 2016 г. № 26/67/13/105/56. URL: https://www.garant.ru/products/ipo/prime/doc/71260608/

9. Специфика меры пресечения в виде домашнего ареста. URL: https:/genproc.gov. $\mathrm{ru} / \mathrm{smi} /$ news/regionalnews/news-1817488/

10. Об утверждении Порядка осуществления ведомственного контроля за соблюдением законодательства Российской Федерации о службе в уголовно-исполнительной системе Российской Федерации: приказ Министерства юстиции Российской Федерации от 22 авг. 2019 г. № 185. URL: https://base.garant.ru/72668264/

11. Уголовно-исполнительный кодекс Российской Федерации от 8 янв. 1997 г. № 1-Ф3 (в ред. от 23 нояб. 2020 г.) // СЗ РФ. 1997. № 2. Ст. 198.

12. Кулешов М.А. Ведомственный контроль и надзор за обеспечением прав, свобод и законных интересов осужденных при режиме особых условий в исправительном учреждении // Человек: преступление и наказание. 2017. Т. 25 (1-4), № 2. С. 288-290.

13. Васильев С.В., Асадов В.В. К вопросу об организации ведомственного контроля за деятельностью уголовно- исполнительных инспекций // Закон и право. 2013. № 5. С. 84-86.

14. Обзор проблемных вопросов, возникающих в деятельности ФКУ УИИ ГУФСИН России по Пермскому краю в процессе исполнения судебных решений в отношении лиц с мерой пресечения в виде домашнего ареста за 12 месяцев 2016 г. URL: https://urist-onlain. ru/osvobozhdenie/ugolovno-ispolnitelnaja-inspekcija-po.html

15. Об организации прокурорского надзора за процессуальной деятельностью органов предварительного следствия: приказ Генеральной прокуратуры Российской Федерации от 28 дек. 2016 г. № 826. URL: https://rulaws.ru/acts/Prikaz-Genprokuratury-Rossii-ot-28.12.2016-№-826/

16. О прокуратуре Российской Федерации: Федер. закон от 17 янв. 1992 г. № 2202-I // Ведомости Съезда народных депутатов Российской Федерации и Верховного Совета Российской Федерации. 1992. № 8. Ст. 366. 